\title{
The Importance of a Thriving Student Organization for a Nonresidential Col- lege Campus
}

\section{Mr. J. William White AIA, Indiana University Purdue University, Indianapolis}

J. William White AIA is a lecturer with the Construction Engineering Management Technology program within the Purdue School of Engineering and Technology in Indianapolis. He is a registered architect who has more than 23 years of varied construction industry experience. Mr. White has undergraduate degrees from Indiana University and Ball State University and a masters degree from Purdue University Indianapolis. He is an active member of the American Institute of Architects and the Construction Specifications Institute. His professional interests include great architecture and all things related to construction innovation.

\section{Mr. Veto Matthew Ray, Indiana University Purdue University, Indianapolis}

Mr. Matt Ray is a lecturer for the Construction Engineering Management Technology Program offered through the Purdue School of Engineering and Technology at Indiana University Purdue University Indianapolis. He currently provides instruction for Soils and Foundations, Construction Cost and Bidding, Construction Project Cost and Production Control as well as managing the Certificate of Training in Asset Management. He is a graduate of Purdue School of Engineering and Technology receiving degrees in Construction Technology, Architectural Technology, and a Masters in Facility Management. His field experience includes residential construction and light commercial. He has been an architectural designer as well as a superintendent for single and multi-family construction projects. Mr. Ray worked as an engineering and design manager in the Building Component Manufacturing Industry for over fifteen years.

\section{Dr. Dan D Koo P.E., Indiana University Purdue University, Indianapolis}

Dr. Koo is an assistant professor in the department of engineering and technology at Indiana University and Purdue University Indianapolis (IUPUI). Dr. Koo is also a registered PE. Dr. Koo's research and professional activities are primarily focused on heavy civil infrastructure system, underground infrastructure system management and development, trenchless engineering, and sustainability. Dr. Koo received a Ph. D in Civil and Environmental Engineering and MS in Construction Management at Arizona State University in 2007 and 2003 respectively; and a BE degree in Civil Engineering in 1999. 


\section{The importance of a thriving student organization for a nonresidential college campus}

\section{Introduction}

The demographics of students pursuing an undergraduate college degree within an urban-based non-residential campus setting are remarkably different from those attending a traditional, residential campus. This is because not only does the student population reside almost entirely off-campus - scattered throughout a typically large, metropolitan area - but it often consists of a generous portion of nontraditional students. Both of these defining characteristics present a "double edged sword" conundrum for the undergraduate college program. On the one hand, they present distinct attributes: the nontraditional student can enrich a classroom with his/her diverse life perspectives and career experiences. The non-residential student won't be distracted by an over-extended social life that has been often documented at large residential institutions. On the other hand, they pose clear detriments: the nontraditional student often faces nontraditional pressures: caring for a spouse, a child (or children), and/or parents all the while managing a fulltime job or even multiple part time jobs. Likewise, the nonresidential student although undistracted by a demanding social life may suffer from the absence of any college-based social activity.

Both of the detriments (non-residential and non-traditional) share a common trait: they can potentially dilute and erode the college experience through noninvolvement, allowing the student to lose focus on his/her studies such that lowered academic achievement and lessened personal performance are the result. The question then becomes, how does an undergraduate program that caters to the needs of a nontraditional / nonresidential student population combat the detrimental effects of noninvolvement? The authors propose one possible solution: a focused student organization that is aligned with an academic program. This organization can supplement a student's college experience by increasing faculty interaction, institutional pride and industry exposure.

\section{Definitions \& demographics}

For the purposes of this paper various terms are defined as follows. Also, the demographics of the institution in which the student organization resides are provided and are compared to a traditional residential campus to establish a frame of reference.

Urban campus: A college campus residing within an urban setting in which the institution doesn't overwhelm or compete with the city's resources. The city is a major regional population center. The institution which includes this student organization, Indiana University Purdue University Indianapolis (IUPUI), has an undergraduate population of 22,271 ${ }^{1}$ students and it resides within Indianapolis, population 844,000 . For comparison, a nearby traditional non-urban university has a student population of 46,817 and resides within a "college town" of 80,405 inhabitants. 
Nonresidential campus: A campus where the vast majority of students live off-campus. For IUPUI, $6 \%$ of the student population resides on campus. ${ }^{2}$ For a traditional residential campus located within the same region, $38 \%$ of the students live on campus. ${ }^{1}$

Nontraditional students: Students that possess one or more of following characteristics: a) entered / reentered education after a major break in their studies, b) are a minimum of 25 years old, c) possess "mature life experience" and/or d) possess an interest in expanding the foundation of their previous education or changing their area of expertise. ${ }^{3}$ Taking into account age alone, $38.9 \%$ of this university's (nontraditional campus) student population is 25 years of age or older. Used for comparison a nearby state institution (residential campus) enrolls a student body with only $3.2 \%$ of its undergraduates exceeding age $25^{4}$. (Figure 1 )

Full time vs. part time: Full time students as defined by this university satisfy a minimum credit hour enrollment of 12 hours per semester. Part time refers to any amount less than 12 credit hours. The university undergraduate population at IUPUI is composed of $24 \%$ part-time students. ${ }^{5}$ At a nearby state institution with a residential campus, its part time student composition is $8.9 \% .^{6}$ (Figure 2)

Student involvement: As stated by Astin, student involvement “... refers to the amount of physical and psychological energy that the student devotes to the academic experience." ${ }^{7}$
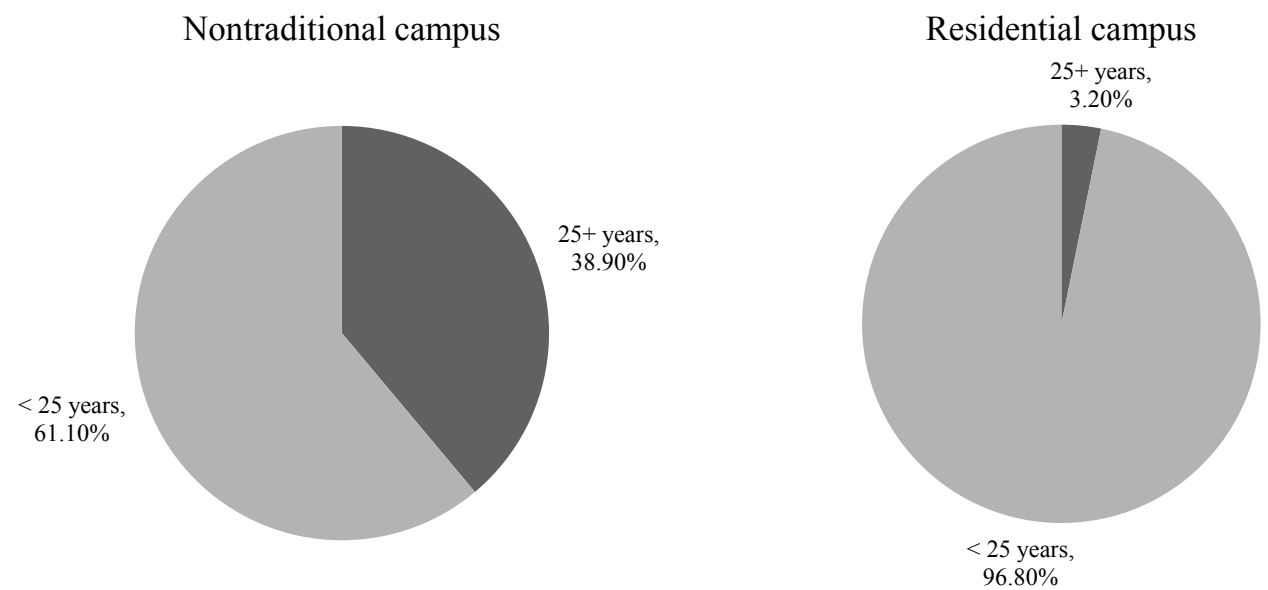

Figure 1. Undergraduate age comparison: nontraditional campus vs. residential campus. 


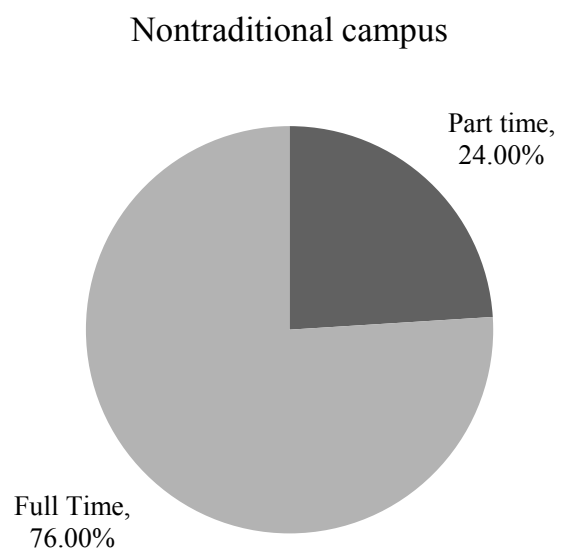

Residential campus

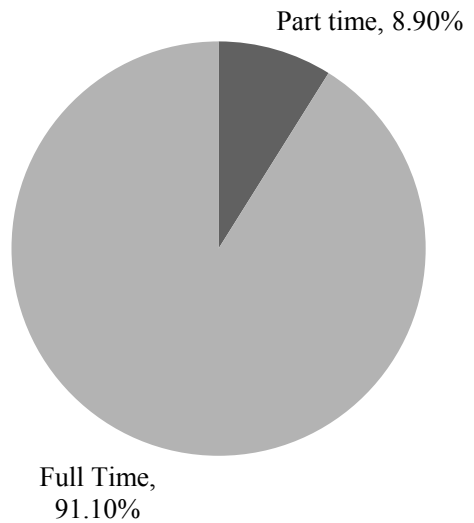

Figure 2. Part time / full time enrollment comparison: nontraditional campus vs. residential campus

\section{Literature review}

The importance of the student organization and extracurricular involvement for the college student cannot be overstated. Many studies unequivocally document the importance of meaningful student engagement as manifested within student organizations. Indeed, Pike and Kuh observed that there is a strong connection between student engagement and positive educational outcomes. "Given the powerful relationship between engagement and positive educational outcomes, it is not surprising that Astin $^{7}$ argued that 'the effectiveness of any educational policy or practice is directly related to the capacity of that policy or practice to increase student involvement." ",8

Moore, Lovell, McGaan et al. ${ }^{9}$ conducted a thorough literature review where an extensive list of benefits is assembled. To summarize, positive correlations appear between student involvement and increased learning, enhanced personal development, greater self-confidence, enhanced interpersonal and leadership skills, improved educational attainment, increased marketability (even more so than grade point average (GPA)) and increased retention and degree completion. Of particular interest for engineering programs, a study was referenced which found engineering recruiters preferred high involvement and medium grades to high grades and medium involvement.

The underachievement of the nontraditional student is well documented. In a 1994 study the U.S. Department of Education found that $43 \%$ of nontraditional students achieved a postsecondary credential as compared to $64 \%$ of the traditional student population. ${ }^{10}$ Moore et al. noted the importance of involvement to both the non-traditional (often synonymous to "adult") and commuting (non-residential) student as they quoted a study by E. Whitt, "Involvement in high quality out-of-class experiences contributes to the learning, development and satisfaction of adult students". 9 Likins stated that the involvement needs of both the adult learner and the commuter are similar and it is a fallacy to assume these students are not interested in being involved. ${ }^{9}$ 
The value of residing on campus is not as clear. While one study indicated that students don't realize an academic advantage by residing on campus versus living off-campus (at home) ${ }^{11}$, Indiana University states plainly that its requirement for freshman to live on campus "... is our policy because we know students who live in our residence halls do better in their classes, are actively involved on campus, get the most out of their college experience, and are more likely to graduate." 12 This policy is supported by Noel who found commuting students possess less commitment to the institution.

\section{Student organization}

This paper focuses on the student organization, the Society of Student Constructors (SSC). The SSC aligns with the construction management program, Construction Engineering Management Technology (CEMT). Perhaps because of its industry focus the program tends to attract a significant number of students that possess a number of nontraditional characteristics. Virtually all students in the program are non-residential.

The SSC currently has a board consisting of four officers (president, vice president, treasurer and secretary). The officers serve one academic year and are elected in the spring semester prior to their term. Within the past year, it became necessary to add an activities chairman whose sole responsibility is to organize and administer the group's construction site visits and industry educational tours. Dues are not required as the organization obtains targeted funding from the campus' student activities office and an annual stipend from an affiliated national organization. It is also the fortunate recipient of gifts from generous corporate donors. While membership is open to anyone interested in topics associated with the building construction industry - including undergraduates and graduates - members are almost exclusively drawn from the CEMT program. Based on its e-mail distribution list, there are currently $72 \mathrm{SSC}$ members. Of these, fewer than $30 \%$ can be considered active members i.e., they regularly attend meetings.

Meetings are the single most frequently occurring activity. Meeting frequency varies by the current SSC administration, typically either once or twice per month not including field trips. Meeting times vary by semester and are dependent on the members' schedules for that particular semester. In the past few years meetings have occurred on Fridays around 12:00 noon. This time is popular as the construction program typically has only two classes scheduled for that day. Meetings are scheduled to last 90 minutes and include free pizza and soft drinks. Meeting attendance varies between 12 to 20 members. Meetings typically consist of an initial presentation by the officers regarding club business, a review of past field trips, upcoming field trips and very often a guest speaker.

Club activities include visits to construction sites and manufacturing facilities, as well as major facility tours. Volunteer activities include an annual alternative spring break trip to New Orleans to assist in the continuing post-Katrina reconstruction efforts, Habitat for Humanity house build participation, local clean-up / construction efforts and occasional volunteer opportunities as they occur throughout the year. 
Alignment with the construction management program is an added benefit. As the infrastructure is already in place, events happening on campus that may be of particular interest to the construction management student can be publicized and discussed in greater detail within the student organization meeting format. Site visits and tours that may be otherwise difficult to schedule within the allotted time frame for a course can be executed by the SSC for the benefit of not only the class but other SSC members. Class topics can be discussed during meetings with greater detail and in a more informal atmosphere.

The nontraditional, nonresidential environment affects the SSC in a variety of ways. Because every student lives off campus - often 30 or more minutes away via personal car - the justification to return to campus must be sufficiently compelling. Evening meetings are very difficult to execute as many of the students desire to be home with their families. Meeting schedules must therefore balance both the most likely time members will be on campus while simultaneously avoiding scheduling conflicts with classes. Likewise, early morning departures for field trips are difficult to schedule. For example a 6:00 a.m. departure from campus requires students leaving home by 5:30 a.m. or earlier. On the positive side, field trip transportation tends not to be a problem as almost every student will have their personal automobile nearby and will be willing to share rides.

The SSC will often benefit from the presence of the nontraditional student population as they tend to assume leadership roles. The past three presidents have been nontraditional students. Also, the nontraditional students tend to exhibit greater commitment to meeting attendance, ask questions of speakers, be more willing to assume leadership positions, and generally take greater advantage of the organization's networking opportunities. A past president once remarked that he didn't realize the value of the organization until he advanced into his senior year and recognized the opportunities it offered. His only regret was that he waited until his senior year to become active.

Outcomes and benefits

Following are the beneficial outcomes of a successful student organization as it applies to a construction management program.

1. Faculty engagement - Chickering and Gamson ${ }^{14}$ noted in their often cited work, Seven Principles for Good Practice in Undergraduate Education, the importance of contact between students and faculty. Indeed, they made it the first principle and declared that it is the single most important factor for student motivation. The authors state: "Knowing a few faculty members well enhances students' intellectual commitment and encourages them to think about their own values and future." The SSC enhances faculty interaction through the close relationship between the officers and the faculty advisors.

Additionally, the organization enjoys meaningful program support as every meeting is typically attended by three to four faculty members. It is also not uncommon to see a few faculty members accompany the organization on its field trips.

2. Leadership - Students who assume officer roles within the SSC encounter all of the challenges of leading a group of individuals, including building consensus, implementing plans / projects, running meetings, maintaining order and successfully collaborating. 
While leadership skills are a virtue regardless of the profession, construction management students particularly benefits from leadership experience as they proceed with their careers and assume the kind of responsibilities common within the industry.

3. Meeting management - In one of the program's core classes, Construction Administration and Specifications, the importance of meetings and the critical role the general contractor / construction manager plays in the execution of these meetings within a construction project is discussed at length. With the SSC the officers personally experience the value of a well-run meeting. The importance of an agenda and minutes become clear through personal experience. The general membership also witnesses firsthand the proper (or improper) execution of a meeting.

4. Industry interaction - As noted previously, the SSC pursues an active field trip agenda which often includes construction site visits. Here interaction with the tour guides typically superintendents, project managers and/or project engineers - inevitably occurs. Additionally, the student organization frequently attends national conferences. The industry exposure at these events is particularly valuable as students not only socially interact with industry leaders but may actually acquire job leads. The CEMT program is also working to increasingly integrate its industry advisory board (IAB) with the student organization's activities through the development of an IAB speaking program. Special guests from the industry are often invited to speak. Presentations by former students who are currently working in the industry are particularly popular. The SSC also serves as an opportunity for potential employers to informally present their companies to students and may even follow-up with a coordinated field trip.

5. Student pride - As the organization increases in prominence, the benefits became visible in some surprising ways. On occasion business cards have been created by the officers complete with their positions on the board. The cards were developed for distribution at a national conference to prospective employers. The current administration is pursuing a shirt with the organization's logo at the popular request of the membership. It is not uncommon to see the e-mail signatures of the officers contain their board titles.

\section{Challenges}

As with any organization there are a myriad of opportunities for improvement. Recruitment of freshmen and sophomores remains particularly challenging. With the blessing of faculty, the officers dutifully make presentations to freshman and sophomore classes however the attendance rate is disappointingly low. This is particularly disturbing as these are the classes that are at most risk for failing to connect with the school in general and the program specifically. This difficulty is all the more daunting given the fact the program resides in a nonresidential, nontraditional campus. Plans have been discussed to provide incentives for these students by working with faculty to possibly offer some form of extra credit. Additionally, an added incentive of a t-shirt give-away has been considered in which students from a targeted freshman class will be eligible to win an SSC t-shirt upon attending one or more meetings.

As the semester progresses meeting attendance in general is difficult to maintain. While enjoying a standing-room-only crowd at the beginning of the fall semester, meeting attendance drops precipitously as the semester progresses such that maybe a dozen students will be attending. 
A common complaint of different SSC administrations is the lack of participation by the membership during the regular meetings. While ice-breakers have been attempted, the significant engagement of all members during a meeting remains an elusive goal. Different alternatives are being considered including a "guest leader" being selected from the group to lead a portion of the meeting.

\section{Conclusion}

Student organizations play a critical role in post-secondary academic achievement. There are numerous studies which link student organizations with successful student development ranging from improved academic performance to increased job marketability. These benefits are particularly important in a nonresidential, nontraditional college program. Non-traditional students face numerous additional pressures which can cause their connection to the academic program to deteriorate and therefore adversely affect their academic performance. Likewise, the academic performance of nonresidential students faces similar detrimental pressure due to their residing off-campus and failing to fully integrate into the college community.

The student organization documented here attempts to mitigate these negative effects by promoting increased social interaction among students of a construction management program. Examples of its benefits have been described which attempt to address the potentially adverse effects of the nontraditional, nonresidential student population. Although the organization faces numerous challenges, it continues to attempt new approaches to better address the special needs of the nonresidential, nontraditional student.

\section{References}

1. US News. Indiana University--Bloomington | Student Life | Best College | US News. 2012. Available at: http://colleges.usnews.rankingsandreviews.com/best-colleges/indiana-universitybloomington-1809/student-life. Accessed December 22, 2013.

2. US News. Indiana University-Purdue University--Indianapolis | Best College | US News. 2014. Available at: http://colleges.usnews.rankingsandreviews.com/best-colleges/indiana-universitypurdue-university-indianapolis-1813. Accessed December 22, 2013.

3. Schuetze HG, Slowey M. Participation and Exclusion: A Comparative Analysis of Non-Traditional Students and Lifelong Learners in Higher Education. Higher Education. 2002;44(3/4):309-327.

4. $\quad$ Purdue University. Purdue University - Enrollment by Age. Purdue University Data Digest 201213. 2012. Available at: http://www.purdue.edu/datadigest/diversity/pg55.html. Accessed December 21, 2013.

5. IUPUI IMIR. Headcount by Demographic and Enrollment Variables :: IUPUI Institutional Reports. Information Management \& Institutional Research. 2012. Available at:

http://reports.iupui.edu/render.aspx/INSTITUTIONAL\%20DATA/HCBYDEMO/IUPUI. Accessed December 21, 2013. 
6. Purdue University. Purdue University - Enrollment by Full-Time and Part-Time. Purdue University Data Digest 2012-13. 2012. Available at: http://www.purdue.edu/datadigest/students/pg11_12.html. Accessed December 21, 2013.

7. Astin AW. Involvement: The Cornerstone of Excellence. Change. 1985;17(4):34-39.

8. Pike GR, Kuh GD. A Typology of Student Engagement for American Colleges and Universities. Research in Higher Education. 2005;46(2):185-209. doi:10.1007/s 11162-004-1599-0.

9. Moore J, Lovell CD, McGann T, Wyrick J. Why involvement matters: A review of research on student involvement in the collegiate setting. College Student Affairs Journal. 1998;17(2):4-17.

10. U.S. Department of Education. Nontraditional Undergraduates / Persistence and Attainment of Nontraditional Students. National Center for Education Statistics. 1994. Available at: https://nces.ed.gov/pubs/web/97578g.asp. Accessed December 23, 2013.

11. Terenzini PT, Pascarella ET, Blimling GS. Students' out-of-class experiences and their influence on learning and cognitive development: A literature review. Journal of College Student Development. 1999;40(5):610.

12. Indiana University. Housing: Student Life: Office of Admissions: Indiana University Bloomington. 2013. Available at: http://admit.indiana.edu/life/housing.shtml. Accessed December 22, 2013.

13. Allen BA. CATALYST v23n3 - The Student in Higher Education: Nontraditional Student Retention. 1993. Available at: http://scholar.lib.vt.edu/ejournals/CATALYST/V23N3/allen.html. Accessed December 22, 2013.

14. Chickering AW, Gamson ZF. Seven Principles For Good Practice in Undergraduate Education. American Association for Higher Education Bulletin. 1987;39:3-7. 